www.jmscr.igmpublication.org Impact Factor (SJIF): 6.379

Index Copernicus Value: 71.58

ISSN (e)-2347-176x ISSN (p) 2455-0450

crossref DOI:_https://dx.doi.org/10.18535/jmscr/v6i4.80

Journal Of Medical Science And Clinical Research

IGM Publication

An Official Publication of IGM Publication

\title{
Prospective Comparative Analysis of Platelets Rich Plasma vs Steroid in Tennis Elbow at Tertiary Heath Care Center- Index Medical College, Indore
}

\author{
Authors \\ Dr Ravindra Gupta, (M.S.) ${ }^{1}$, Dr Vinay Tantuway (M.S.) ${ }^{2}$ \\ ${ }^{1}$ Assist Prof. Index Medical College Indore \\ ${ }^{2}$ Prof. Index Medical College Indore, India \\ Corresponding Author \\ Dr Ravindra Gupta (M.S.) \\ Email: joint03mamc@gmail.com
}

\begin{abstract}
Introduction: This study is to compare results of inj steroid and inj PRP in tennis elbow condition locally. People that requires repetitive supinaton \& pronation of forearm with elbow in near full extension are more predisposed to develop this condition. It was originally described as inflammatory process but current consensus is that tennis elbow is initiated as multiple micro tear most often within the origin of the $E C R B^{C A M P} 13 T H 2599$. Corticosteroid injection have anti-inflammatory pontential whereas PRP injection have regenerative capacity.

Materials and Method: All patients were taken from OPD of index medical college, Indore. Duration was from January 2017 to March 2018. It was a prospective study. After patient selection by inclusion and exclusion criteria PRP or steroid injections were given on OPD basis. Full informed consent was taken prior to participate in study. Before putting patients in steroid group or PRP group everything has been explained to patients about procedure including charges. Patient chose group themselves by their own choices.

Total of 70 patients were investigated and diagnosed having tennis elbow. 38 patients chose for local steroid injection and 32 patients opted for PRP injection.

Results and Discussion: Our study shows that PRP injection is much better \& safer option than steroid injection in terms of pain improvement and functional outcome. The probable reason may be as has been described in introduction TENNIS ELBOW is an degenerative process rather than an inflammatory process. Steroid acts as an anti-inflammatory substance and PRP is a regenerative material. So PRP works properly against the pathology and gives long term results.

Conclusion: In conclusion, local injection of autologous PRP as compared to local steroid injection appeared to be a promising form of therapy for tennis elbow. It is both safe (prepared from autologous blood) and effective in relieving pain and improving function. PRP therapy is much costlier than steroid injection but in long term it is fount to b cost effective (less requirement of future intervention). The current available data support that repeated steroid injections are deleterious and may lead to serious consequences even tendon rupture. However sustained efficacy of this therapy should be further evaluated in long-term follow-up studies that include a larger number of patients.
\end{abstract}

Keywords: PRP injection, steroid injection, Tennis elbow. 


\section{Introduction}

This study is to compare results of injection steroid and injection PRP in tennis elbow condition locally. Tennis elbow (lateral epicondilitis) is pain at lateral condyle of humerus at insertion of dorsi-flexors of wrist. It occurs more frequently in non- athletes than athletes with peak incidence in early fifth decade with no gender predisposition. People that require repetitive supinaton \& pronation of forearm with elbow in near full extension are more predisposed to develop this condition. It was originally described as inflammatory process but current consensus is that tennis elbow is initiated as multiple micro tear most often within the origin of the $\mathrm{ECRB}^{\mathrm{CAMP}}{ }^{13 \mathrm{TH}} 2599$. Histo-pathological findings includes granulation tissues, microrupture, degenerative changes $\&$ there is very less inflammation $^{1,2}$. So tennis elbow is more of a degenerative condition rather than inflammatory condition of tendons. Tendons get very little blood supply that is why injured tendons heal notoriously slowly. Platelets secretes growth factors \& creates healing environment; so the idea of PRP is to inject a patient's own platelets at the site of a tendon injury is to induce healing without risk of any side effects. Current traditional practice is to inject steroid injection at the point of maximal tenderness after failure of conservative management for 6 months. This therapy immediately relieves pain but for short term only but it doesn't promote healing. Corticosteroid injection may weaken tendon and may leads to its rupture also.

PRP injection (latest still controversial treatment for tennis elbow) is prepared from autologous blood. It releases high concentrations of plateletderived growth factors such as vascular endothelial growth factor (VEGF), transforming growth factor (TGF)- $\beta 1$, insulin-like growth factor (IGF) and platelet derived growth factor (PDGF), ${ }^{3,4}$ that enhance wound, bone, and tendon healing. $\frac{5}{\text { PRP }}$ platelets are initially activated by thrombin and collagen. After activation by releasing growth factors it attracts undifferentiated cells into the newly formed matrix and trigger cell division. ${ }^{6}$ It inhibits cytokine release from macrophages \& improves tissue healing and regeneration. Minor side effects may include slight pain or bruising at the injection site following the procedure.

\section{Material and Methods}

All patients were taken from OPD of index medical college, Indore; Madhya-pradesh. Duration was from January 2017 to March 2018. It was a prospective study. After patient selection by inclusion and exclusion criteria PRP or steroid injections were given on OPD basis. Full informed consent was taken prior to participate in study. Before putting patients in steroid group or PRP group everything has been explained to patients about procedure including charges. Patient chose group themselves by their own choices.

Total of 70 patients were investigated and diagnosed having tennis elbow. 38 patients chose for local steroid injection and 32 patients opted for PRP injection.

\section{Inclusion Criteria}

$>$ Patients aged 18 years or greater of either sex with clinical diagnosis of lateral epicondylosis based on site of pain and pain elicited with active extension of wrist in pronation and elbow in extension.

$>$ One of the following tests being positive: wrist extension (Cozen's test), Mill's maneuver, jar lifting test

\section{Exclusion Criteria}

$>$ history of acute elbow trauma

$>$ any previous elbow surgeries

$>$ Thrombocytopenia, pregnancy, malignancy

$>$ patients requiring anti-platelet medication for the treatment of ischemic heart disease, cerebro-vascular accidents or other medical conditions

$>$ elbow arthritis

$>$ Other causes of elbow pain such as osteochondritis dissecans of capitellum, posterior interosseous nerve syndrome, cervical disc syndrome, synovitis of radiohumeral joint, cervical radiculopathy, fibromyalgia. 
$>$ Local steroid at same site with in previous 1 month.

\section{Method of Steroid Injection (Group A):-}

$2 \mathrm{ml}$ of methylprednisolone $(40 \mathrm{mg} / \mathrm{ml})$ taken in syringe. Supine patient with elbow flexed to $90^{\circ}$ with forearm in pronation; injection site is painted and draped. Radial head is palpated while pronating and supinating the forearm. The needle $(22 \mathrm{G})$ is introduced proximal to the radial head on lateral epicondyle at the point of maximum tenderness and around the tendon of ECRB. Multiple pricks were made in the tendon (peppering technique) and steroid injected slowly. Patients were advised to rest in the outpatient block for approximately $1 \mathrm{hr}$. after 1 hour we checked for skin condition at the site of injection. Now we applied an above elbow slab for 2 weeks for total restriction of movements at elbow and wrist. After 2 weeks gradually mobilization started. Patients were advised for not to indulge in activities that requires repetitive supination and pronation atleast for 3 months. Wrist band support \& elbow cap support were also advised after 2 weeks of slab. After the procedure, the patient was prescribed broad spectrum antibiotics (cephalosporins) for 3 days. All NSAIDS were strictly avoided for 7 days.

\section{Method of PRP Preparation \& Injection Procedure (Group B):-}

Blood was drawn from the patient in ACD-A vial $(10 \mathrm{~mL})$ preloaded with citrate phosphate dextrose (CPD). ACD-A Anticoagulant Citrate Dextrose Solution, Solution A, USP $(2.13 \%$ free citrate ion), is a sterile, non-pyrogenic solution. ACD-A is the only anticoagulant product approved by the United States Food \& Drug Administration for the use in Autologous PRP Systems for the preparation of Platelet-Rich Plasma (PRP). Blood was taken in ACD-A vial; centrifugation done in two spins. First spin was at $1800 \mathrm{rpm}$ for $15 \mathrm{~min}$ to separate erythrocytes and white blood cells from other blood components and a second spin was at $3500 \mathrm{rpm}$ for $10 \mathrm{~min}$ for further concentration of platelets. We get about 2 to $3 \mathrm{~mL}$ of platelet rich plasma. It increases number of platelets to three to five times from baseline.

The patient is placed supine with elbow flexed to $90^{\circ}$ with forearm in pronation; injection site is painted and draped. Radial head is palpated while pronating and supinating the forearm. Under strict aseptic precautions local anaesthetic (2\% xylocaine) given. After this The needle (18 G) was introduced proximal to the radial head on lateral epicondyle at the point of maximum tenderness and around the tendon of ECRB. Multiple pricks were made in the tendon (peppering technique) and PRP injected slowly. Now patients were advised to rest in the outpatient block for approximately $1 \mathrm{hr}$. after 1 hour we checked for skin condition at the site of injection. Now we applied an above elbow slab for 2 weeks for total restriction of movements at elbow and wrist. After 2 weeks gradually mobilization started. Patients were advised for not to indulge in activities that requires repetitive supination and pronation at least for 3 months. Wrist band support \& elbow cap support were also advised after 2 weeks of slab. After the procedure, the patients were prescribed broad spectrum antibiotics (cephalosporins) for 3 days. All NSAIDS were strictly avoided for 7 days.

Data were collected by verbal conversation either face to face or telephonic interview. Written documentation of pain (VAS- Visual Analog Score) and evaluation of limitation of function (DASH- Disability of Arm Shoulder and Hand) was done before and after the procedure.

\section{Results \& Discussion}

Corticosteroid group patients had much faster pain relief. But 6 months after treatment, PRP group patients were much more likely to have less pain and more function than those who received the corticosteroid.

PRP group patients were kept getting better over the next months in terms of pain \& functional measures (VAS \& DASH scores).

At 6 months PRP group patients reported 68\% improvement in pain \& $76 \%$ improvement in disability scores. Whereas corticosteroid group 
patients reported $28 \%$ improvement in pain \& $35 \%$ improvement in disability scores.

5 out of 32 PRP group patients required corticoid injection to get pain relief. 2 patients out of these still didn't improved and required surgery. 16 out of 38 patients in steroid group required repeat steroid injection for pain relief. 6 patients out of these still needed surgical intervention.

Our study shows that PRP injection is much better $\&$ safer option than steroid injection in terms of pain improvement and functional outcome. The probable reason may be as has been described in introduction TENNIS ELBOW is an degenerative process rather than an inflammatory process. Steroid acts as an anti-inflammatory substance and PRP is a regenerative material. So PRP works properly against the pathology and gives long term results.

\section{Conclusion}

In conclusion, local injection of autologous PRP as compared to local steroid injection appeared to be a promising form of therapy for tennis elbow. Steroid injection appears to be effective in short term whereas PRP gives persistent results. PRP is both safe (prepared from autologous blood) and effective in relieving pain and improving function. PRP therapy is much costlier than steroid injection but in long term it is found to be cost effective (less requirement of future intervention). The current available data support that repeated steroid injections are deleterious and may lead to serious consequences even tendon rupture. However sustained efficacy of this therapy should be further evaluated in long-term follow-up studies that include a larger number of patients.

\section{References}

1. Du Toit, C; Stieler, M; Saunders, R; Bisset, L; Vicenzino, B (2008). "Diagnostic accuracy of power Doppler ultrasound in patients with chronic tennis elbow". British Journal of Sports Medicine. 42 (11): $\quad$ 572-576. doi:10.1136/bjsm.2007.043901. ISSN 030 6-3674.
2. Jump up^ Nirschl RP (October 1992). "Elbow tendinosis/tennis elbow". Clin Sports Med.11 (4): 85170. PMID 1423702.

3. Weibrich G, Kleis WK, Hafner G, et al.. Growth factor levels in platelet-rich plasma and correlations with donor age, sex, and platelet count. Journal of CranioMaxillofacial Surgery. 2002; 30:97-102.

4. Landesberg R, Roy M, Glickman RS. Quantification of growth factor levels using a simplified method of platelet-rich plasma gel preparation. Journal of Oral and Maxillofacial Surgery. 2000; 58:297300.

5. Edwards SG, Calandruccio JH. Autologous blood injections for refractory lateral epicondylitis. J Hand Surg. 2003; 28:272-278.

6. Bhanot S, Alex JC. Current applications of platelet gels in facial plastic surgery. Facial Plast Surg. 2002; 18:27-34.

7. Geaney LE, Arciero RA, DeBerardino TM, et al.. The effects of platelet-rich plasma on tendon and ligament: basic science and clinical application. Op Techn Sports Med. 2011; 19:160-164.

8. Eppley BL, Woodell JE, Higgins J. Platelet quantification and growth factor analysis from platelet-rich plasma: implications for wound healing. Plast Reconstr Surg. 2004; 114:1502-1508.

9. Everts PA, Knape JT, Weibrich G, et al.. Platelet-rich plasma and platelet gel: a review. J Extracorp Tech. 2006; 38:174.

10. Mishra A, Woodall J, Vieira A. Treatment of tendon and muscle using platelet-rich plasma. Clin Sports Med. 2009; 28:113125.

11. Connell DA, Ali KE, Ahmad M, et al.. Ultrasound-guided autologous blood injection for tennis elbow. Skeletal Radiol. 2006; 35:371-377.

12. Gani N, Butt MF, Dhar SA, et al.. Blood injection in the treatment of 
refractory tennis elbow. Internet Journal of Orthopedic Surgery. 2007; 6(4):5473.

13. Bisset L, Beller E, Jull G, et al.. Mobilisation with movement and exercise, corticosteroid injection, or wait and see for tennis elbow: randomised trial. BMJ. 2006; 333:939. 